Original Research Paper

\title{
Quantitative Analysis of the Pb Concentration in Dust Fall in Zahedan in the Winter of 2014
}

\author{
${ }^{1}$ Sara Abdollahi, ${ }^{2}$ Akram Karimi, ${ }^{3}$ Meysam Madadi, \\ ${ }^{4}$ Kaveh Ostad-Ali-Askari, ${ }^{5}$ Vijay P. Singh and ${ }^{6}$ Saeid Eslamian \\ ${ }^{1}$ Environmental Science Department, Yazd University, Yazd, Iran \\ ${ }^{2}$ Department of Environmental Science, College of Environment, Karaj, Iran \\ ${ }^{3}$ Department of Environment Science, Gorgan University of Agriculture Science and Natural Resources, Gorgan, Iran \\ ${ }^{4}$ Department of Civil Engineering, Isfahan (Khorasgan) Branch, Islamic Azad University, Isfahan, Iran \\ ${ }^{5}$ Department of Biological and Agricultural Engineering \& Zachry Department of Civil Engineering, \\ Texas A and M University, 321 Scoates Hall, 2117 TAMU, College Station, Texas 77843-2117, USA \\ ${ }^{6}$ Water Engineering Department, Isfahan University of Technology, Isfahan, Iran
}

Article history

Received: $10-03-2018$

Revised: 23-04-2018

Accepted: 11-05-2018

Corresponding Author:

Kaveh Ostad-Ali-Askari

Department of Civil

Engineering, Isfahan

(Khorasgan) Branch, Islamic

Azad University, Isfahan, Iran

Email: koa.askari@khuisf.ac.ir

\begin{abstract}
Dust is considered as one of the atmospheric phenomena that inappropriately influences the environment. Falling dust contains particles with the size of 100 microns or less, which falls from atmosphere on the surface of the earth. This study aimed at determining the $\mathrm{Pb}$ concentration in falling dust samples in order to investigate the urban pollution caused by this element. To investigate the quantitative changes in falling dust lead and its spatial analysis, sampling was performed using 30 sediment traps for 3 months in the winter of 2014. These traps were installed in 30 stations on the roofs of some buildings in Zahedan which were about 1.5 meters high. As the results indicated the Cumulative average of lead concentration was $97.32 \pm 5.4 \mathrm{mg} / \mathrm{kg}$ in the winter. Correspondingly, scrutinizing lead zoning map revealed that the lowest lead level was measured at the Azadegan station in the winter, whilst the Behdasht station received the highest lead level.
\end{abstract}

Keywords: Dust Fall, Heavy Metals, Pollution, Cumulative Average

\section{Introduction}

Rapid urbanization and constant demand for infrastructure development in urban areas have led to disruptions and consequently to a major reduction in the quality of urban environments (Joshi et al., 2009). Dust is commonly a mixture of solid or soluble particles or both suspended in the air (Sheikhi et al., 2010). Recently, two methods named theoretical calculation and laboratory measurements have been used for measuring falling dust (Azimzadeh et al., 2010). In the laboratory method, samplers and MDCO (Marble Dust Collectors) are used to collect horizontal and vertical dust. The MDCO was designed by Ganer in 1975. This trap consists of a plastic container and one or two rows of glass arches that can be installed on the ground or attached to a vertical base. The plastic containers can be used for different purposes, among which circular dishes are better than rectangular ones, since the effects of wind direction on rectangular dishes are more obvious. The diameter of the spheres used is 1.6 centimeters (Jia and Huang, 2008). Dust storm phenomenon is pinpointed as a dire issue in various regions of the world including Iran (Akbari et al., 2012). While most dust exists in the atmosphere originally comes from fine particles, which are more prevalent in arid and semi-arid regions of the world. In fact, the dust generation can be a response to the change in land cover, in which the role of human activities along with the normal situation of the geographical environment cannot be ignored. Raeispour (2007) Recently, an increase in dust level has caused serious problems, especially in areas close to the arid regions. Nakano et al. (2004) arid and semi-arid Asian areas are the most significant hotbeds of dust in the world. Among the dust-affected areas, the Middle East is one of the world's most polluted places located in hot and arid desert belt and is truly fragile (Lashkari and Keykhosravi, 2007). Studies related 
to the frequency of dusty days in the country indicated that the central holes in Iran have experienced the highest number of dusty days (Alijani, 1997). Most of the dust source areas are in the Middle East and Southwest Asia, the Arabian Peninsula and the surrounding deserts, which are active during a period of April to July (Goossens and Rajot, 2008). Dust is one of the atmospheric phenomena causing inappropriate environmental outcomes. Dust causes climate change on a global and local scale and also leads to changes in biological, geological and chemical cycle and also in human environment. Mineral particles generated by dust can influence cloud composition, cloud characteristics and atmospheric deposition. Atmospheric dust pollution inhibits sunshine penetration and can result in reduction of agricultural products up to $5-30 \%$ (Shahsavani, 2010). Since, dust transmission rout is broad; this phenomenon can also change soil and its biological trends (Goudie, 2009). Dust consists of a mixture of solid and soluble particles or both suspended in the air which are able to steadily stay suspended for a long time and can even move many kilometers away from their original source. These particles along with some evacuated mineral particles can increase the concentration of some other pollutants including heavy metals having harmful influence on human and other creatures (Sheikhi et al., 2010). Human activities cause an inclination in the level of heavy metals in the environment (Pourali and Taghizadeh, 2011). Dust plays a focal role in the transmission of environmental pollutants (Csavina et al., 2012). $\mathrm{Pb}$ is one of the heavy metals entering the environment in various ways by human (Hosseini et al., 2013). In recent years, due to the elimination of lead from petrol, its entry into the urban environment has decreased significantly, but the accumulation of its previous uses has remained in the environment (Moayedi et al., 2007). The lead half-life in blood, soft tissue and bone tissue is 2-4 weeks, 4 weeks and 27.5 years, respectively (Karimpour, 1993). Increasing the concentration of lead in air dust increases the concentration of lead in children's blood. If infants were exposed to more than $10 \mu \mathrm{g}$ of lead per day, their IQs will be decreased dramatically (Lanphear and Roghmann, 1997). Numerous diseases can be mentioned caused by lead poisoning including anemia, nephropathy, neuropathy, psychiatric disorders and excessive hypertension (Samara and Voutsa, 2005). Many studies have been conducted on the concentration of lead in particulate particles in different parts of the world. Moreno-Grau et al. (2002) calculated the maximum concentration of lead to be $1000 \mathrm{mg}$. $\mathrm{kg}$ in the city of Cartag. Salamatian (2013) calculated the maximum amount of lead in the falling dust of Isfahan to be $4.07 \mathrm{mg} . \mathrm{kg}$ in winter. Focused on a study in Cordoba province in central Argentina investigating the concentration average, rate of precipitation of heavy metals and rare elements in the falling dust, as well as the study of its relation with the surface soil and the amount of these elements in wheat grains and have identified the origin of these elements.

\section{Materials and Methods}

\section{Introducing the Study Area}

The present study is conducted in Zahedan, with an area of about 557 square kilometers and a population of 574000 people. It is known to be $1385 \mathrm{~m}$ high from sea level and is between geographical latitudes of 605125 eastern longitudes and 293045 northern latitudes. According to the obtained meteorological data, the annual rainfall mean is $72 \mathrm{~mm}$, the maximum of annual temperature average is $42.5^{\circ} \mathrm{C}$ and the minimum of annual temperature average is $-12.6^{\circ} \mathrm{C}$.

\section{Falling Dust Sampling and Determining it's Lead}

Systematic random sampling method was used to determine the sampling regions. Consequently, 30 stations were selected in the city. In order to investigate falling dust, a Marble Dust Collector (MDCO) was used. This sampler was placed at a height of $1.5 \mathrm{~m}$ above the roof where sampling was carried out for three months from December 2014 to February 2014. At the end of each month, trapped dust was carefully collected from the MDCO. A total of 90 dust samples were taken from 30 stations in the city. At the same time as each sample was taken, the geographic coordinates of each point were written down using GPS in the UTM system. During this 3-month period, trapped dust in MDCO was carefully collected on a monthly basis and weighed accurately using a scale of $0.001 \mathrm{~g}$. The samples were analyzed using ISO11466. Extraction was performed to determine the concentration of heavy metals using nitric acid and hydrochloric acid (Black, 1965). To measure lead concentration in dust samples, the atomic absorption spectrometry of the Analytic jena-350 flame model was used. Descriptive statistics parameters including mean, maximum, minimum, elongation and skewness of total lead metal concentration were obtained by SPSS V. 16 software. The data were normalized by KolmogorovSmironov test. Having prepared the information file from the lead metal variables, the statistical indices of the classical lead data were analyzed and Arc GIS 9.3 software input file was provided. To investigate spatial and frequency distribution of $\mathrm{Pb}$ in the city considering obtained results from different stations, zoning map of study area was provided by Kriging method using Arc GIS 9.3 software (Fig. 1). 


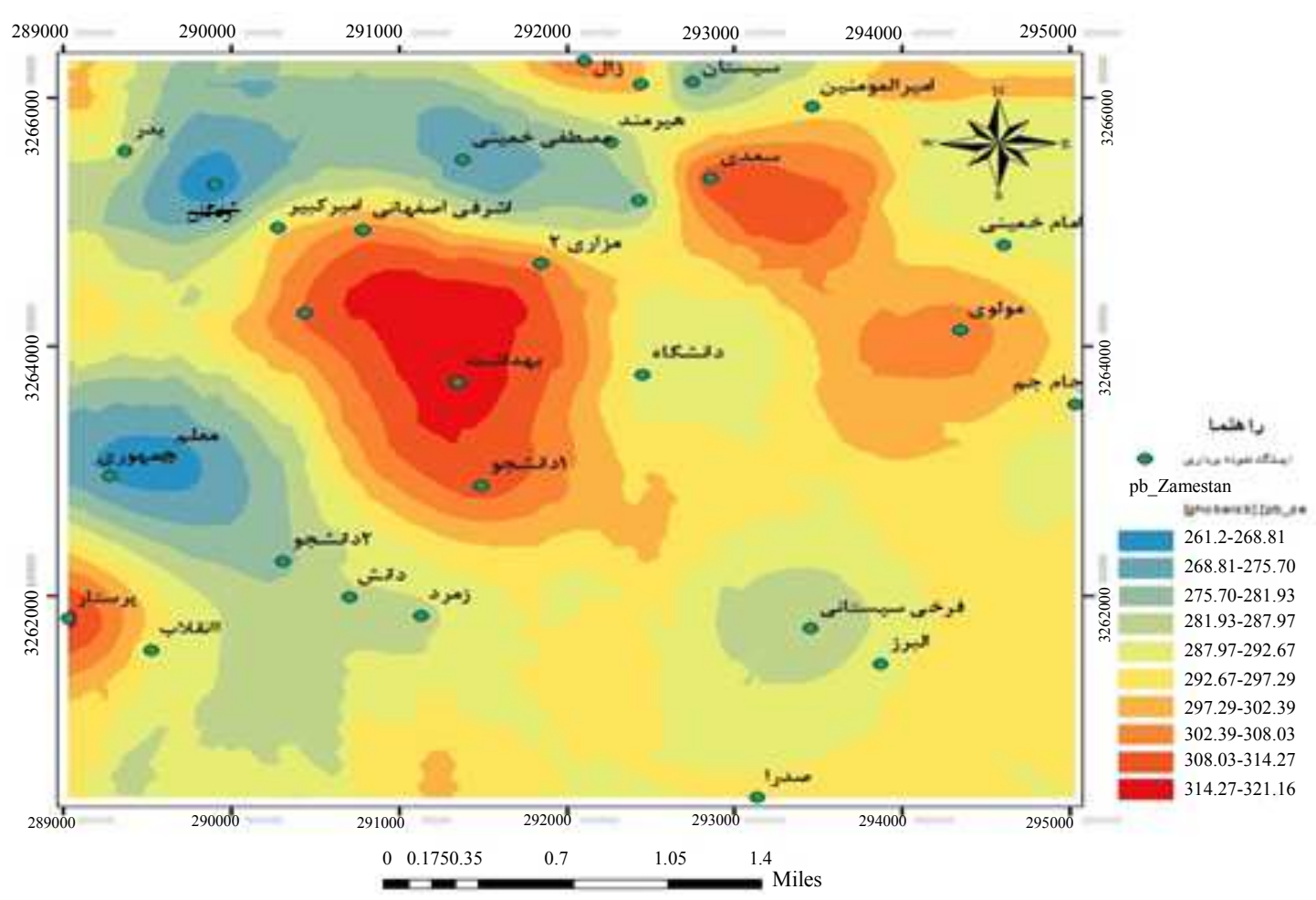

Fig. 1: Zoning map of $\mathrm{Pb}$ metal of dust falling in the winter 2014

Table 1: Indices and the environmental potential level of heavy metallic pollutants (Salamatian, 2013; Saeedi et al., 2012; Wei et al., 2010)

\begin{tabular}{llll}
\hline Qualitative class of pollution & Pollution index (PI) & The environmental risk level of each metal & Ecological risk (Er) \\
\hline Low & $\mathrm{PI}<1$ & Low risk & $\mathrm{Er}<40$ \\
Medium & $1<\mathrm{PI} \leq 3$ & Medium risk & $40<\operatorname{Er} \leq 80$ \\
High & $\mathrm{PI} \geq 3$ & Significant risk & $80<\mathrm{Er} \leq 160$ \\
- & - & High risk Very high danger & $160<\mathrm{Er} \leq 320 \mathrm{Er} \geq 320$ \\
\hline
\end{tabular}

\section{Pollution Index Calculation}

In environmental studies especially when the geochemical distribution of elements in the environment is the result of a combination of human and natural factors, changes in trends should be evaluated using pollution indices

\section{Pollution Index (PI)}

To determine soil contamination to heavy metals, the contamination factor was used. Based on this factor, the amount of heavy metals is measured relative to its natural value and the amount of soil pollution is calculated as:

$$
P I=C n / B n
$$

The ecological risk (Er) for each element is also calcula- ted according to the following formula:

$E r=T r . P I$ where, $C n$ is the concentration of metal in each sample and $B n$ is the standard value of this metal in the soil and the $\operatorname{Tr}$ is the factor of the toxic reaction. According to Hecanson's suggestion, the value of $\operatorname{Tr}$ for lead metal is 5 (Akbari et al., 2012). Table 1 depicted how these indices are categorized.

\section{Results}

\section{The Amount of Lead Metal in Dust Fall}

Table 2 depicted descriptive statistics of lead metal and Table 3 demonstrated the index of pollution and ecological risk associated with lead metal in winter.

Table 2 descriptive statistics of lead between different months of the winter 2014, season shows that the highest concentration of lead in February, with an average $75.24 \pm 13.82 \mathrm{mg}$. $\mathrm{kg}$ and the lowest level in January, with an average $1.03 \pm 7.66 \mathrm{mg}$. $\mathrm{kg}$. 
Table 2: Descriptive statistics of lead metal in different months in winter (mg. kg)

\begin{tabular}{|c|c|c|c|c|c|c|c|}
\hline & Arithmetic mean (mg.kg) & St.d & Min & Max & Skewness & Kutosis & k-s \\
\hline Junary & 1.03 & 7.66 & 90.00 & 118.25 & 0.06 & -0.61 & 0.95 \\
\hline February & 75.24 & 13.82 & 50.20 & 99.90 & -0.07 & -0.88 & 0.91 \\
\hline March & 1.12 & 10.49 & 102.85 & 148.75 & 1.80 & 3.67 & 0.15 \\
\hline
\end{tabular}

Table 3: Lead pollutant indices of falling dust in the winter of 2014 (mg. kg)

Cumulative average of $\mathrm{Pb}$ metal in winter 2014

Pollution index in winter 2014

Ecological risk in winter 2014

97.32 1.20 6

Also, according to the results of KolmogorovSmirnov test (column 8 of Table 2), p-value data of lead metal in winter months was more than 0.05 , so the data have normal statistical distribution. Table 2 also shows that the maximum measured value of lead with 148.75 mg. kg for the Behdasht station is in March 2014. The minimum amount of lead measured at MostafaKhomeini station in February is $50.20 \mathrm{mg}$. kg.

Also, according to Table 3, the results indicated that the average lead concentration in winter was $97.32 \pm 5.40$ $\mathrm{mg}$. $\mathrm{kg}$, which was the highest concentration related to the Behdasht station with the value of $107.05 \mathrm{mg}$. $\mathrm{kg}$ and the lowest measured value the Azadegan station was $87.07 \mathrm{mg}$. kg.

As the results of the Table 3 indicated, the amount of PI in winter is more than one; therefore it is classified in the medium level of pollution. The ecological risk index is less than 40 in the winter $(\mathrm{Er}=6)$, so the lead metal in winter 2014 shows a low environmental risk.

The zoning map of the region demonstrated the distribution and frequency of lead in the falling dust of the whole area of Zahedan that the lowest level of lead were measured at the Azadegan, Moallem and Jomhuri stations, whilst Behdasht station experienced the highest level of the lead metal (Fig. 1).

\section{Discussion}

As mentioned above, in most cities in arid and semiarid regions, the main cause of air pollution is haze. Lead is one of the most harmful heavy metals for human health. In a study conducted by Shi et al. (2010), they examined the urban and suburban areas of Shanghai. The findings showed that all heavy metals other than arsenic were found to be more than the original source and the origin of copper, zinc, nickel, cadmium, lead and chromium was in urban, transportation areas and for coal mercury. In the suburbs, the source of lead, arsenic and cadmium is from traffic jams, nickel and chromium from the industry and mercury is originating from household waste. In this vein, Qingjie et al. (2008) used the ecological risk indices, cumulative contamination and the level of promoted contamination to calculate heavy metal contamination in Bijing Parks of China. The findings indicated that most of the soils in the park are non-polluted or have low pollution. Feng et al. (2008) studied the dust of Jinan City in northern China. Samples were analyzed to study copper, lead, zinc and cadmium. The results showed that all four elements had a significant accumulation in dust particles of this city and their concentrations were more than the basic. The results of this study indicated that the concentration of lead in Zahedan city dust exceeds measured values in Yazd and in Behbahan (Akbari et al., 2012). The results of zoning of the lead of falling dust showed that the highest concentration of lead was related to Salamat station and the lowest concentration was related to Azadegan station. Studies have shown that the main source of lead released is from vehicle fuel. Hence, high vehicle traffic can be a factor in increasing the concentration of heavy metals.

\section{Conclusion}

Comparing the obtained results of lead level in this study with other studies in other cities requires knowing about extraction and the method of extraction of heavy metals. In this study, the amount of heavy metal in the falling dust was investigated, it is suggested to study the amount of other heavy metals such as $\mathrm{Zn}, \mathrm{Ni}, \mathrm{Cu}$ and etc in the dust of Zahedan. Getting advantages of such studies, we can obtain information on the contamination and environmental hazards of these elements and we can also determine the source of the production and dissemination of these elements and examine methods of control, reduction and prevention of the resulting effects. Also, the amount of exposure of citizens to these elements can be taken into consideration and by comparing the results with research carried out in other border cities of the country, the process of transmission of these elements can be reached.

\section{Acknowledgement}

In the end, thanks and gratitude to all the colleagues and professors who co-operated with this research.

\section{Funding Information}

All the financial costs of this work, including: sampling costs, sample analysis, publication of the work and ... are provided by the authors of the work. 


\section{Author's Contributions}

Sara Abdollahi, Akram Karimi, Vijay P. Singh and Saeid Eslamian: Write manuscript.

Meysam Madadi and Kaveh Ostad-Ali-Askari: Write manuscript and revise it.

\section{Ethics}

In this article, all ethical principles related to scientificresearch articles such as: validity and authenticity, originality, data collection in a standard manner, integrity and accuracy of research and ... are observed.

\section{References}

Akbari, Atefeh, Azimzadeh, Hamid-Reza and Ekhtesasi, et al., 2012. Quantitative analysis of dust falling. Proceedings of the National Conference on the Desert Case Study, (DCS' 12), Behbahan City.

Alijani, B., 1997. Iran's weather. Payame Noor University of Tehran.

Azimzadeh, Hamid-Reza, Montazer-Ghaem, Masoud and Torabi-Mirzaei et al., 2010. Measurement of dust falling in the Yazd city using the MDCO trap during the summer quarter of 2010. Proceedings of the 2nd National Conference on Wind Erosion and Storms of Dust, (ESD’10), Yazd University.

Black, C.A., 1965. Methods of Soil Analysis. Part 2: Chemical and Microbiological Properties. 1st Edn., American Society of Agronomy, Madison, pp: 801.

Csavina. J., J. Field, M.P. Taylor, S. Gao and E.A. Betterton et al., 2012. A review on the importance of metals and metalloids in atmospheric dust and aerosol from mining operations. Sci. Environ., 433: 58-73. DOI:10.1016/j.scitotenv.2012.06.013

Hosseini, E., Mitra-Sadat, Azimzadeh, Hamid-Reza and Kalantari-Islami et al., 2013. Investigating the concentration of lead in dust falling in Yazd city. Proceedings of the 3rd National Conference on Wind Erosion and Dust Storms, (EDS' 13), Yazd University, Yazd.

Feng. J.L, L.P. Zhu, J.T. Ju, L.P. Zhou and X.L. Zhen et al., 2008. Heavy dust fall in Beijing, on April 16-17, 2006: Geochemical properties and indications of the dust provenance. Geochem. J., 42: 221-236. DOI: 10.2343 /geochemj.42.221

Gharibi, F. 2015. Investigation of physical and chemical changes of some heavy dusts of dusts on Ahwaz City in February 2015 based on environmental assessment. Environmental Sciences, Natural Resources and Desertification College, Yazd University.

Goossens, D. and J.L. Rajot, 2008. Techniques to measure the dry aeolian deposition of dust in arid and semi-arid landscapes: A comparative study in West Niger. Erath Surface Process. Landforms, 33: 178-195. DOI: 10.1002/esp.1533
Goudie, A.S., 2009. Dust storms: Recent developments. J. Environ. Manage., 90: 89-94. DOI: $10.1016 /$ j.jenvman.2008.07.007

Joshi, U.M., K. Vijayaraghavan and R. Balasubramanian, 2009. Element composition of urban street dusts and their dissolution characteristics in various aqueous media. Chemosphere, 77: 526-533.

DOI: 10.1016/j.chemosphere.2009.07.043

Karimpour, M., 1993. The study of the sources of drinking water in the city of Hamedan in terms of heavy metals. Thesis of School of Public Health, Medical University Tehran.

Lanphear, B.P. and K.J. Roghmann, 1997. Pathways of lead exposure in urban children. Environ. Res., 74: 67-73. DOI: 10.1006/enrs.1997.3726

Lashkari, H. and G.H. Keykhosravi, 2007. Statistical synoptic analysis of dust storm in Khorasan Razavi Province (1993-2005). Natural Geography Res., 40: 17-33.

Moayedi, S.N., A. Fani, H.R. Mohajerani and A. Seyed-Ali-Mehbod, 2007. Blood lead levels in arak residents with clinical syndromes. J. Faculty Med., 32: 79-75.

Moreno-Grau, S., J.A. Cascales-Pujalte, M.J. MartÍnezGarcĺa, M.J. Angosto and J.M. Moreno et al., 2002. Relationships between levels of lead, cadmium, zinc and copper in soil and settleable particulate matter in cartagena (Spain). Water Air Soil Pollut., 137: 365-383. DOI: 10.1023/A:1015541116891

Nakano, T., Y. Yokoo, M. Nishikawa and H. Koyanagi, 2004. Regional Sr-Nd isotopic ratios of soil minerals in northern china as Asian dust fingerprints. Atmosphere. Environ., 38: 3061-3067. DOI: 10.1016/j.atmosenv.2004.02.016

Pourali, M., and A.H. Taghizadeh, 2011. Study of causes and source of dust formation in Khuzestan Province. J. Educ. Develop. Geograp., 94: 8-13.

Qingjie, G., D. Jun, X. Yunchuan, W. Qingfei and Y. Liqiang, 2008. Calculating pollution indices by heavy metals in ecological geochemistry assessment and a case study in parks of beijing. J. China Uni. Geosci., 19: 230-241. DOI: $10.1016 / \mathrm{S} 1002-0705(08) 60042-4$

Saeedi. M, L.Y. Li and M. Salmanzadeh, 2012. Heavy metals and polycyclic aromatic hydrocarbons: Pollution and ecological risk assessment in street dust of Tehran. J. Hazardous Mater., 227-228: 9-17. DOI: 10.1016/j.jhazmat.2012.04.047

Raeispour, K., 2007. Statistical analysis of the phenomenon of dust in Khuzestan province. MSc Thesis, Sistan and Baluchestan University.

Salamatian, S., 2013. Investigating the variations in the amount of dust and determining some of its physical and chemical properties in the December 2012 to joune 2013. MSc Thesis in Environmental Science, Yazd University. 
Samara. C. and D. Voutsa, 2005. Size distribution of airborne particulate matter and associated heavy metals in the roadside environment. Chemosphere, 59: 1197-1206.

DOI: 10.1016/j.chemosphere.2004.11.061

Shahsavani, A., 2010. The effect of dust storms on health and the environment. J. North Khorasan Uni. Med. Sci., 2: 45-56.

Sheikhi, Zahra, Jafari-Mousavi, Ali and Akbar et al., 2010. Evaluation and measurement of total suspended solids and heavy metals in the air Ahwaz and compare the results with environmental standards. Proceedings of the National Conference on Health and Sustainable Development, (HSD’ 10) Islamic Azad University of Bandar Abbas.
Shi, G., Z. Chen, C. Bi, Y. Li and J. Teng et al., 2010. Comprehensive assessment of toxic metals in urban and suburban Street Deposited Sediments (SDSs) in the biggest metropolitan area of China. Environ. Pollut., 158: 694-703.

DOI: $10.1016 /$ j.envpol.2009.10.020

Jia, Q. and Y. Huang, 2008. Coarse dust around mining areas: A study of available dust collectors and their efficiency. Department of Civil and Environmental Engineering, Lulea University of Technology, Luleå, Sweden.

Wei, B., F. Jiang, X. Li and S. Mu, 2010. Heavy metal induced ecological risk in the city of Urumqi, NW China. Environ. Monit. Assess., 160: 33-45.

DOI: $10.1007 / \mathrm{s} 10661-008-0655-1$ 